\title{
Asian Influenza Surveillance
}

\author{
ALEXANDER D. LANGMUIR, M. D., MARIO PIZZI, M. D., WILlIAM Y. TROTTER., M. D., \\ and FREDERICK L. DUNN, M.D.
}

$I^{x}$ N MAY 1957 immediately after Dr. Maurice R. Hilleman, then with the Walter Reed Army Institute of Research, identified influenza viruses from the Hong Kong epidemic as "distinctly different from type A strains previously isolated from this country and Europe," steps were undertaken to meet the potential threat of an epidemic in the United States. It was anticipated that the new strain would be introduced into this country constantly by travelers returning from epidemic areas in the Far East. Single sporadic cases would probably be commonplace among such persons but difficult to recognize. Localized outbreaks among selected highly crowded population groups, particularly in the military forces, could also be expected, but no extensive epidemic spread was thought likely until fall.

All Epidemic Intelligence Service officers and all epidemiological personnel of the Communicable Disease Center, both at headquarters and in the field, were alerted for first priority duty in the investigation of influenza and influenzalike disease cases and outbreaks. During June few reports of cases were received, and these largely concerned personnel on military bases and ships. The first outbreaks appeared, surprisingly, among the crews of several destroyers at Newport Naval Station, R. I. In mid-June sharp outbreaks occurred among Navy recruits in San Diego and Army recruits at Fort Ord, Calif. At the end of June, an outbreak de-

The authors are all with the Epidemiology Branch, Communicable Disease Center, Public Health Service, where Dr. Langmuir is branch chief and Dr. Pizzi, chief of the Surveillance Section. Drs. Trotter and Dunn are both in the Influenza Surveillance Unit. veloped among high school girls at a conference on the campus of the University of California School of Veterinary Medicine at Davis, Calif. A nurse epidemiologist with the Communicable Disease Center participated with California State health officials in the investigation of this outbreak.

From Jume 28 to July 3 an outbreak of influenza appeared in Grinnell, Iowa, at a Westminster Fellowship Conference, which was attended by 1,680 delegates from more than 40 States and 10 foreign countries. A delegation of more than 100 students from California, at least one of whom had been exposed at the Davis conference, developed influenza en route and clearly introduced it to the other delegates. When this conference was disbanded, the infection was carried to all parts of the country. It was evident by this time, however, that the infection was being seeded in manifold ways.

In the early part of July, it became apparent that the routine morbidity reporting channels from the States to the National Office of Vital Statistics were not sufficient to handle the steadily increasing load of detailed reports. Accordingly, the Influenza Surveillance Unit was formally established in the Communicable Disease Center for the purpose of supplementing, but in no way replacing, the regularly established functions of the National Office of Vital Statistics. This surveillance unit was designed along lines similar to those initiated for the poliomyelitis surveillance reports in 1955 . From its inception, the Influenza Surveillance Program was a joint undertaking of the Epidemiology Branch, with all of its Epidemic Intelligence Service officers and field personnel reporting continually and in detail, and the Respiratory Disease Unit of the Virus and Rick- 
ettsia Section of the Laboratory Branch, with its rapidly expanding system of collaborating influenza diagnostic and reference laboratories.

The information from these extensive sources was consolidated with the large amount of data reported directly to the National Office of Vital Statistics from the States and military services. Lengthy reports were prepared weekly and distributed to all State health officers, State laboratory directors, State epidemiologists, and many others having interests or responsibility in the study and control of influenza. The first of these reports was published July $9,1957$.

\section{Nationwide Spread}

During July, Asian strain influenza was disseminated widely through the country. Outbreaks occurred chiefly in closed population groups such as children's camps and military installations. California camps were most heavily affected.

From July 11 to 18 an International Boy Scout Jamboree held at Valley Forge, Pa., was attended by a total of 53,000 Scouts and leaders from every State and from several foreign countries. At the beginning of the encampment there was evidence of influenza among Scouts from Sacramento, San Francisco, and Ios Angeles, Calif., and from Louisiana and Puerto Rico. En route to the Jamboree, when the Scouts were in close contact for extended periods of time, many became ill. Laboratory studies have since demonstrated that their disease was Asian influenza. During the encampment many additional cases occurred among contacts of the originally involved groups, but no large epidemic developed in the camp. Three Epidemic Intelligence Service officers were stationed at Valley Forge to gather basic epidemiological and laboratory data. Additional cases occurred among Scouts on the way home, although again most of these were in the California and Iouisiana contingents.

In the latter part of July, a number of new outbreaks occurred in children's camps throughout the country. Most of these could have been related either to the Boy Scout Jamboree or to other previously known outbreaks. There was very little evidence of community- wide outbreaks affecting children and adults during .July.

Influenza continued to appear in sporadic fashion during August. Certain incidents increased its spread and gave warning of future developments. Migrant workers, exchange students, Scouts, and others continued to disseminate the disease. However, during early August a major communitywide outbreak occurred in Tangipahoa Parish, La. It was readily apparent that this outbreak was related to the opening of summer school sessions in this rural area where children were required to work at the harvest later in the season. Spread from school children to other members of families was clearly demonstrated. Shortly afterward, nearby New Orleans bagan to experience the first major urban outbreak. These outbreaks were investigated by I)r. J. I). Martin of the Isouisiana State Department of Health and two members of the Epidemic Intelligence Service. The belief that a nationwide epidemic might well begin with the general opening of public schools was further supported when several Mississippi counties also experienced communitywide outbreaks originating in schools that reopened in mid-August.

By late August there was no longer any doubt that a major nationwide influenza epidemic could be expected. For this reason, the Surgeon General of the Public Health Service called members of the Association of State and Territorial Health Officers to a special meeting on influenza to be held August 27 and 28 . The purpose of this meeting was to review the influenza situation, to consider methods of control, and to coordinate all health activities to this end. One recommendation of the meeting resulted in a broadening and intensification of the CDC influenza surveillance activities. It was recommended that the States $(a)$ adopt a program of epidemic reporting first by counties to the States and from them to the Public Health Service; (b) adopt a standard method of gathering and reporting information on outbreaks; and (c) sample absentee rates in selected schools and industries.

To facilitate this reporting by the States, the Communicable Disease Center designed a set of five forms. One of these was to be used for influenza reporting to the National Office 
Figure 1. Weekly pneumonia and influenza deaths

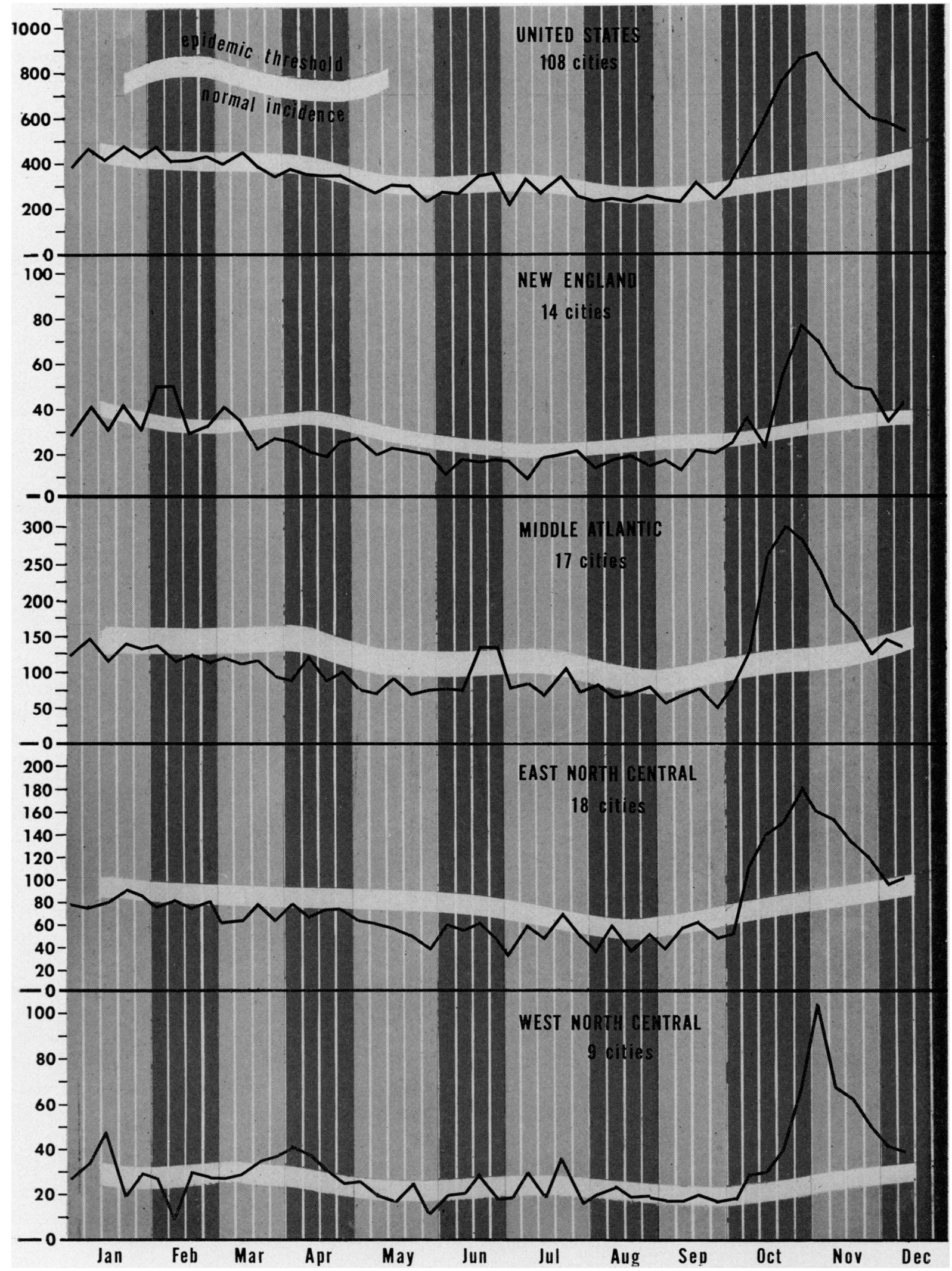


in the United States through December 13, 1957.

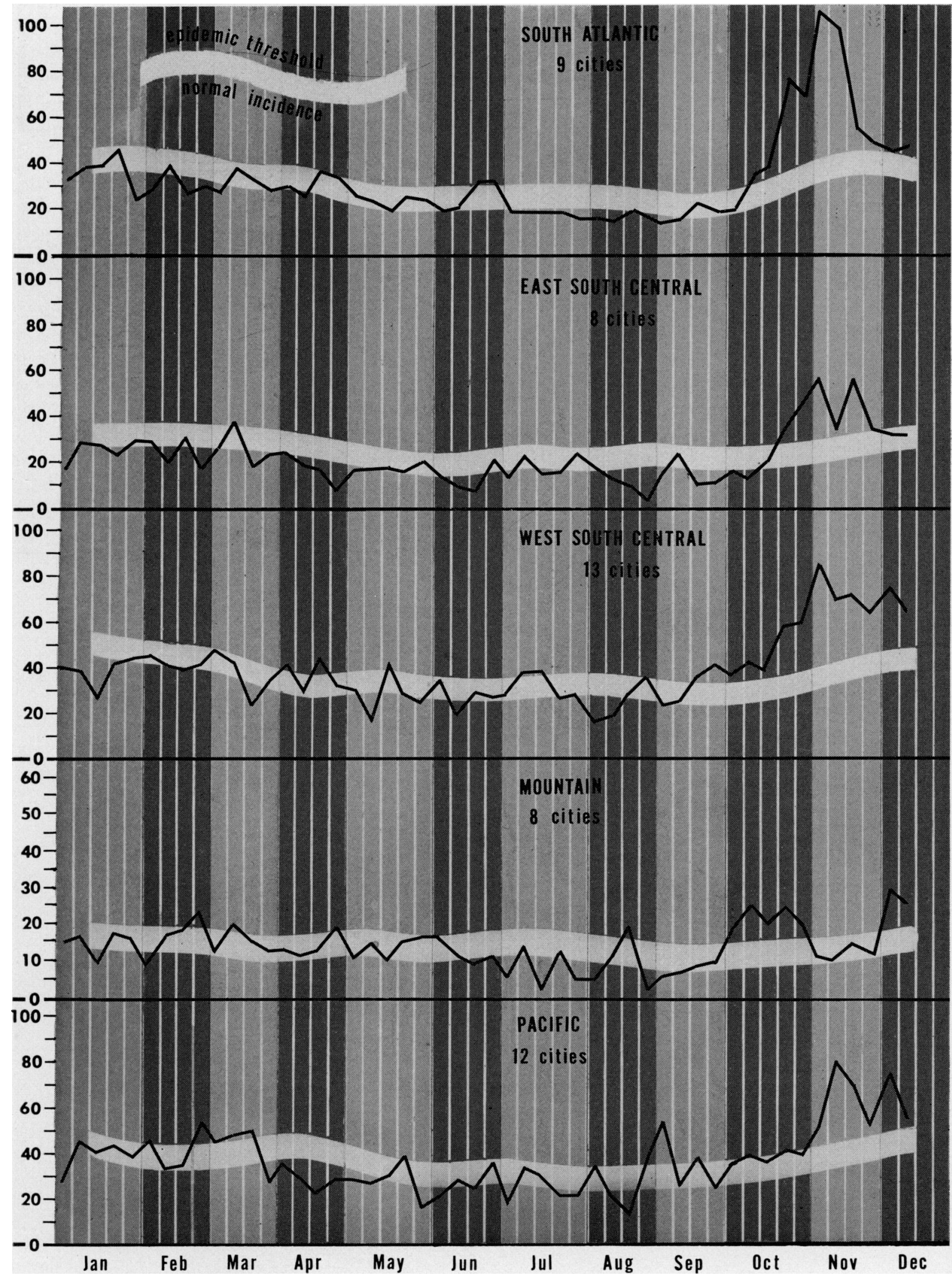

Vol. 73, No. 2, February 1958 
of Vital Statistics and to the Center, and the others were to aid States in collecting data. On September 17 instructions and samples of each form were attached to the influenza surveillance report and sent to each State health officer, along with blanks for obtaining additional forms. Approximately 10,000 forms were mailed to the States to initiate their reporting systems, and an additional 45,000 have been sent to them since then in response to direct requests. Information gained from these forms has made it possible to estimate the geographic spread of the disease through the States.

In early September, as schools and colleges began to open, the number of influenza outbreaks increased greatly. Reports of new inuroductions of the disease by Mexican migrant laborers and foreign students continued. Communitywide epidemics spread further in the Mississippi-Louisiana region. Influenza vaccine was now being released in quantity, and weekly production and release figures were included in the surveillance report. In order to measure the effects of influenza precisely, weekly analyses were prepared of excess mortality from influenza and pneumonia in 108 major United States cities (fig. 1). Shortly after the first release of vaccine, reports began to appear of nonallergic vaccine-associated deaths. Prompt investigation of these reports showed them to be poorly substantiated, and this fact was noted in the surveillance reports.

During the month of September, many Epidemic Intelligence Service officers participated in studies of local epidemics in order to determine further the behavior of the disease. Epidemic Intelligence Service officers also participated with the CDC Laboratory Branch in studies of vaccine effectiveness at Atlanta Federal Penitentiary and conducted studies of vaccine reactions in various population groups.

Early in October excess influenza and pneumonia mortality began to rise in the West South Central division, and by the end of the month the Nation as a whole was clearly experiencing increased deaths. Voluntary reporting

Figure 2. Localized outbreaks and countywide epidemics of Asian influenza, through October 27, 1957.

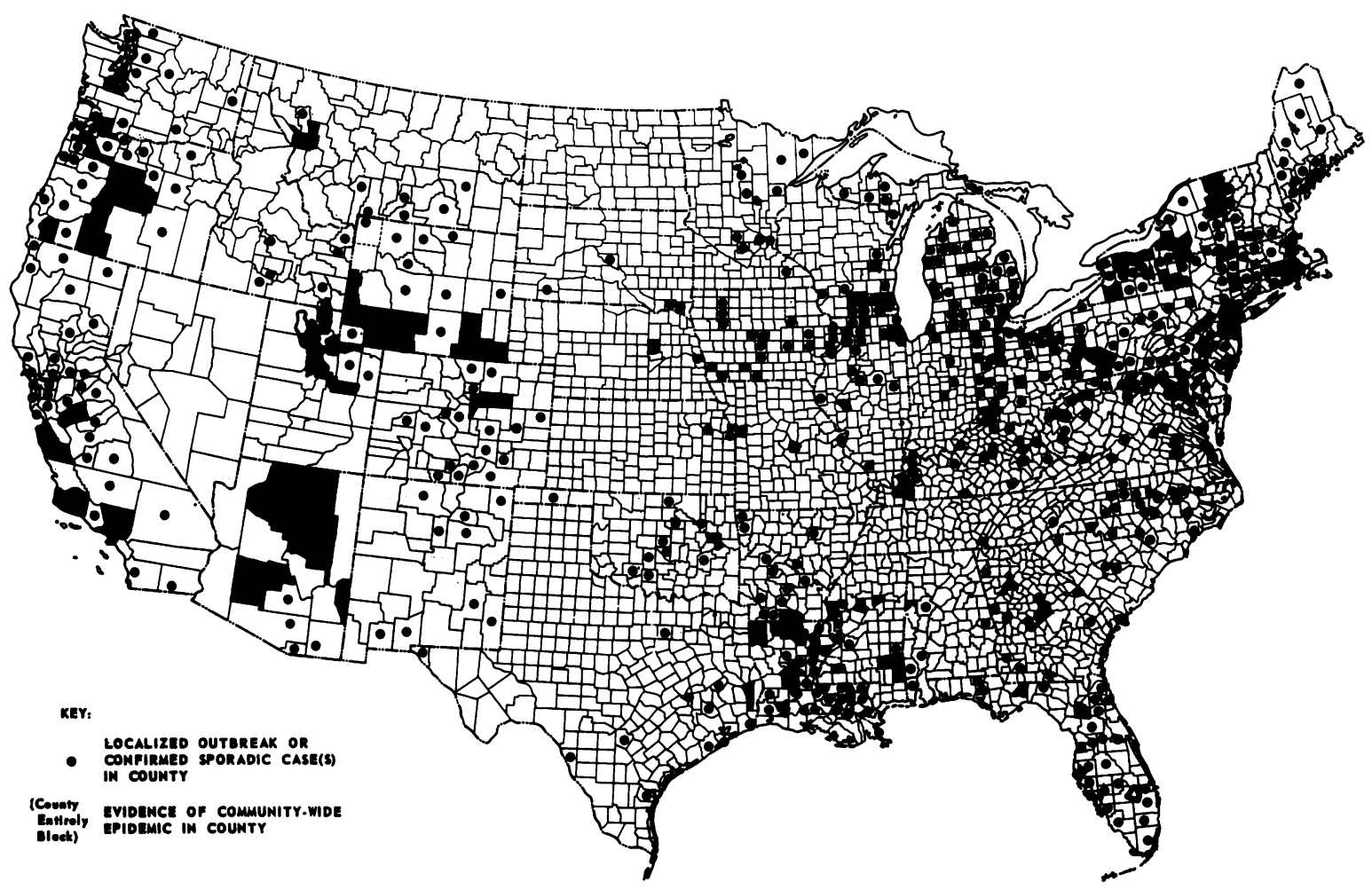


Figure 3. Geographic spread of Asian influenza, by county, through December 2, 1957.

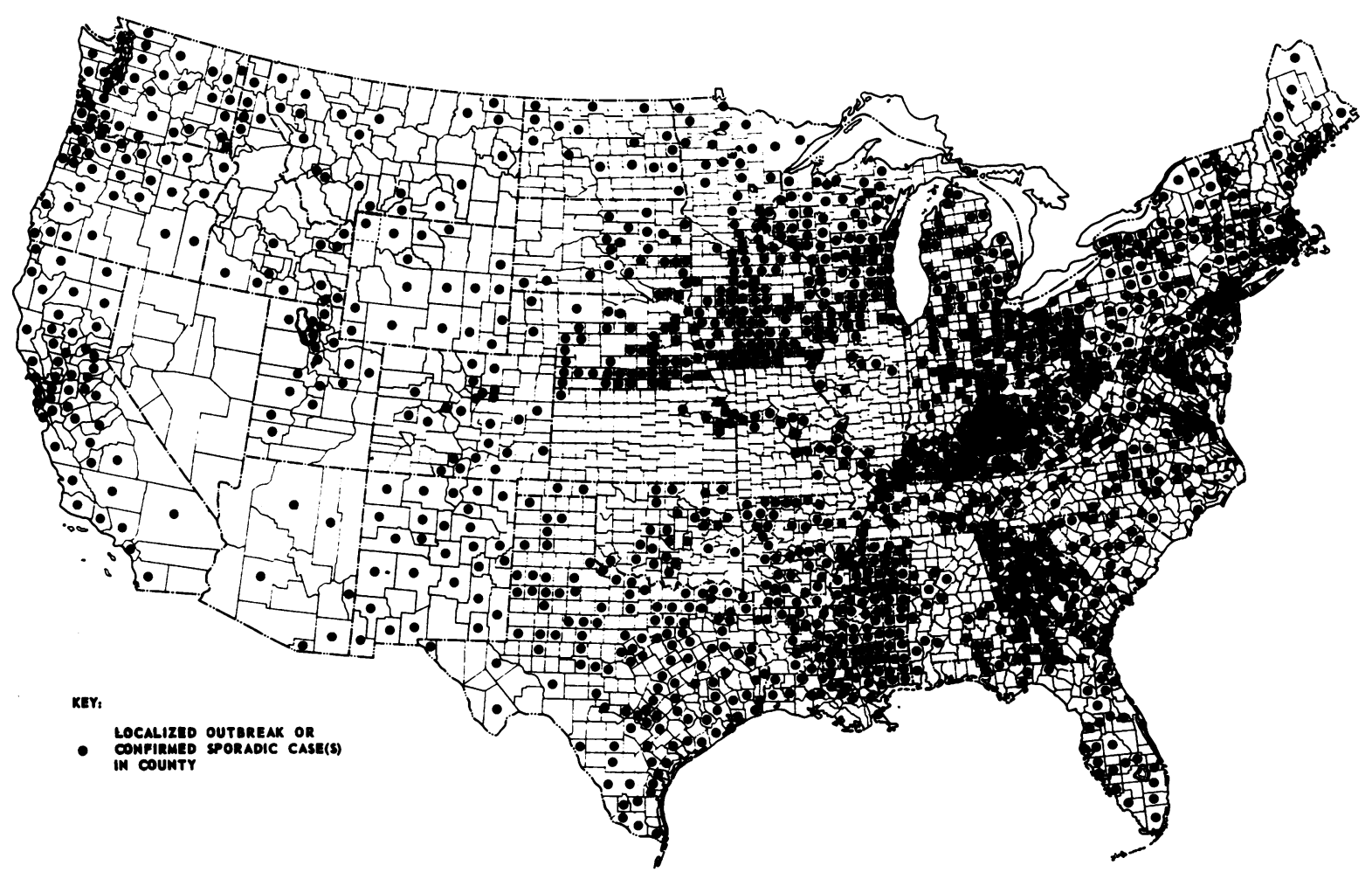

of detailed influenza case histories resulted in a collection of valuable information regarding deaths and complications. This information was interpreted and published in the influenza surveillance reports to aid in treatment and stimulate further investigations. On October 15, through cooperation with certain corporations, it was possible to present industrial absentee data for 36 major United States cities. Several cities showed significantly increased absenteeism early in October, and most cities were affected before November. By this time influenza had reached at least 20 percent of the counties, and the county map (fig. 2) was beginning to lose its significance as an indicator of incidence. At this time effort to distinguish localized outbreaks from countywide epidemics was discontinued, and a new map was made to show simple geographic spread by counties (fig. 3).

A further measure of the epidemic was provided by the U. S. National Health Survey as preliminary data which the Influenza Surveillance Unit was permitted to publish. From all the available methods of measurement, it was apparent that the epidemic was reaching a peak early in November, and by late November mortality, absenteeism, and new cases appeared to be on the decrease.

Despite the decline of the epidemic in late November 1957, the surveillance program continued in force because of the possibility of a second epidemic wave. The surveillance group continued its efforts to describe the epidemic and to define those areas in need of immediate or retrospective study.

\section{Discussion}

Although much data remain to be gathered, it is already possible to give a general picture of the 1957 epidemic as obtained through surveillance methods. Morbidity has been high, with clinical cases in approximately 25 percent of the population. But the mortality has been relatively low, in the range of 7,000 excess deaths from pneumonia and influenza. There has been no evident change in the severity of the cases with the progress of the epidemic, although it was possible to define certain special 
risk groups such as pregnant women and persons with chronic cardiac and respiratory conditions. The present epidemic will probably result in more deaths than the $\mathbf{A}^{\prime}$ influenza epidemic of 1953 and may eventually prove to be more severe than the A epidemic of 1943. However, it is in no way comparable to the pandemic of 1918 and is less severe as measured by mortality than nine epidemics that have occurred since 1920. There has been a rather consistent pattern of initial involvement of high school children, followed by spread to elementary school children and adult populations. Industrial absenteeism increased a few days before excess mortality rose in a given urban community. Many deaths have occurred in the older age groups and in the debilitated. Staphylococcal pneumonia has been a prominent cause of death, although nonbacterial pneumonia has resulted in many deaths.

\section{Sure Cures, 1918}

"The present epidemic has given rise to the publication of numerous 'sure cures' and methods more or less plausible to the lay mind. The advocates of some of these have addressed long communications to Secretary McAdoo, to Surgeon General Blue, to the War Department, or other Government agencies. Hundreds of them have written to editors of newspapers. In general the suggestions fall into several groups.

"First comes the individual who has a specific remedy, the formula of which he is ready to give to the world for a price. One such writer reminds the Surgeon General of the million dollars that Congress has appropriated for combating influenza, and offers to sell his secret for 'a reasonable sum.'

"Next comes the person with the pseudoscientific treatment, sometimes 'isotonic sea water,' sometimes 'ozono therapy,' and again 'harmonic vibrations.' One such writer, well known to the New York health authorities, addressed the Surgeon General from his present residence, the State Hospital for the Insane.

"The list might be continued, but the suggestions are largely variations and repetitions of what has already been cited.

"The United States Public Health Service urges the public to remember that there is as yet no specific cure for influenza, and that many of the alleged 'cures' and remedies now being recommended by neighbors, nostrum vendors, and others do more harm than good. The chief reliance must be on fresh air, nutritious food, plenty of water, cheerful surroundings, and good nursing. If any specific like a vaccine or serum is found to have value the Public Health Service will give the matter wide publicity." 